
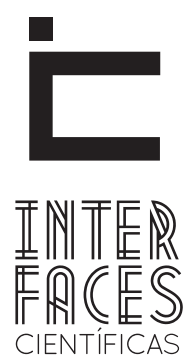

EDUCAÇÃO

ISSN IMPRESSO 2316-333X

ISSN ELETRÔNICO 2316-3828

DOI 10.17564/2316-3828.2015v3n3p23-32

\title{
EDUCAÇ̃̃O LUSO-BRASILEIRA: O COLÉGIO DE SANTO ANTÃO E AS AULAS DA ESFERA
}

Célio Juvenal Costa ${ }^{1}$

Natália Cristina de Oliveira ${ }^{3}$
Gilmar Alves Montagnoli²

\section{RESUMO}

Tratamos aqui do Colégio de Santo Antão, fundado pela Companhia de Jesus, no século XVI, em 1553, em Lisboa, o qual, especialmente devido às suas Aulas de Esfera, se destacou no cenário educacional e científico lusitano. Com a vinda da Companhia de Jesus a Portugal, em 1540, passam a ser implantados, no Reino e em todo o Império, Colégios dirigidos pelos seus membros, os quais, posteriormente, não terão mais somente fins religiosos. Assim, nesse contexto, apresentamos, primeiramente, os principais objetivos, características e dificuldades da ordem inaciana no território português, bem como aspectos quanto à sua implantação, seus objetivos iniciais e sua consolidação. Posteriormente, abordaremos a história do Colégio de Santo Antão, sua origem e principais características, estabele- cendo uma discussão pontual acerca de uma das aulas mais importantes da instituição: a Aula de Esfera, intrínseca à Matemática. Aquela instituição de ensino cresceu rapidamente e foi para além do quinhentos, tornando-se o maior e mais destacado centro de Ciências e Astronomia de Portugal. Partimos do pressuposto de que estudar a história do Colégio de Santo Antão contribui para se compreender como eram consideradas as inovações no ensino luso, ainda que jesuítico, no Portugal e, também, no Brasil do séc. XVI.

\section{PALAVRAS-CHAVE}

Colégio de Santo Antão. Companhia de Jesus. Portugal. Século XVI. 


\section{ABSTRACT}

We here at the College of Santo Antão, founded by the society of Jesus, in the 16th century, in 1553, in Lisbon, which, especially due to its ball Classes, excelled in educational and scientific scenario lusitano. With the advent of the society of Jesus in Portugal, in 1540, are deployed in the Kingdom and throughout the Empire, schools run by its members, which subsequently will no longer have religious purposes only. So, in this context, we, first of all, the main objectives, characteristics and difficulties of the Ignatian Portuguese territory order, as well as aspects regarding their deployment, their initial objectives and its consolidation.Later, we will discuss the history of the College of Santo Antão, its origin and main characteristics, establishing a timely dis-

\section{RESUMEN}

Estamos aquí en el colegio de Santo Antão, fundada por la compañía de Jesús, en el siglo XVI, en 1553, en Lisboa, que, debido especialmente a sus clases de baile, destacado en el escenario educativo y científico lusitano. Con el advenimiento de la sociedad de Jesús en Portugal, en 1540, están desplegados en el Reino y en todo el Imperio, dirigidas por sus miembros, que posteriormente no tendrá fines religiosos sólo escuelas. Así, en este contexto, en primer lugar, los objetivos, características y las dificultades del territorio portugués Ignaciana orden, así como aspectos relativos a su despliegue, sus objetivos iniciales y su consolidación. Más tarde, vamos a discutir la historia de la Universidad de Santo Antão, su origen y características principales, estableciendo una oportuna discusión acerca cussion about one of the most important lessons of the institution: Ball class, the intrinsic math. That educational institution grew rapidly and was in addition to the five hundred, becoming the largest and most prominent science and Astronomy Centre of Portugal. We start from the assumption that study the history of the College of Santo Antão contributes to understanding how were considered innovations in teaching Portuguese, although in Portugal and Jesuit, also in Brazil. XVI.

\section{KEYWORDS}

Colégio de Santo Antão. Society of Jesus. Portugal. The 16th Century. de una de las lecciones más importantes de la institución: clase de baile, las matemáticas intrínsecas. Esa institución educativa creció rápidamente y fue además de los quinientos, convirtiéndose en el más grande y más prominente de la ciencia y la astronomía centro de Portugal. Partimos de la suposición de que estudio la historia de la Universidad de Santo Antão contribuye a la comprensión como consideraban a las innovaciones en la enseñanza del portugués, aunque en Portugal y jesuita, también en Brasil XVI.

\section{PALABRAS CLAVE}

Colégio de Santo Antão. Compañía de Jesús. Portugal. El siglo XVI. 


\section{INTRODUÇÃ̃O}

Escrever sobre o Colégio de Santo Antão e sobre a Aula da Esfera é discutir a atuação da Companhia de Jesus, em Portugal, no século XVI. Este exercício vai além das observações acerca do trabalho realizado pelos padres de iniciar um movimento religioso que tinha como principal objetivo propagar a fé cristã católica, pois, contempla, também, a influência que tiveram nos âmbitos: social, político, educacional e religioso do período. Compreender tais influências é fundamental à História e Historiografia da Educação na Modernidade e, em especial, a Luso-Brasileira.

Para abarcar as discussões que norteiam o texto, é fundamental que se considere a ordem inaciana que, a serviço do papa, desenvolveu suas missões num período de reformas da Igreja. Em 1534, Inácio de Loyola, aluno da Universidade de Paris, dedica-se juntamente com seus primeiros companheiros, Pedro Fabro e Francisco Xavier, a fazer voto de pobreza e fundar a Companhia de Jesus. Além dos citados, posteriormente outros integrantes aderem ao movimento reformador, tornando-se, também, pilares da nova ordem religiosa: Simão Rodrigues de Azevedo (único português entre eles), Inácio Diogo Laines, Afonso Salmeirão, o espanhol Nicolau Afonso, Cláudio Jaio, Pascháesio Broet e João Codure.

No ano de 1540, com a Bula Regimini Militantis Ecclesiae, o Papa Paulo III, aprova a constituição da Ordem e autoriza, oficialmente, o funcionamento da Societas lesu (Sociedade de Jesus). Com os integrantes citados, o líder Inácio de Loyola estabelece os principais votos religiosos a serem seguidos: pobreza, caridade e obediência, além de um quarto voto de obediência irrestrita ao papa em caso de missões. Após composta e instituída, a Companhia de Jesus, atendendo a um pedido do papa, vai a Portugal, ainda em 1540. Após isso, os inacianos passam a implantar naquele reino os colégios por eles dirigidos.
Os colégios jesuítas, a princípio, atendiam alunos somente com fins religiosos, para que os discentes viessem a fazer parte da Companhia. Porém, a posteriori, passam também a aceitar alunos que não tivessem por meta seguir a Societas lesu. Dessa forma, os filhos dos súditos portugueses passam, também, a fazer parte do alunado, desde que se sujeitassem às regras impostas igualmente aos candidatos jesuítas. Com o passar do tempo, tais centros pedagógicos tinham como lei orgânica uma publicação de 1599, o Ratio Atque Institutio Studiorum, documento tido como o método pedagógico da Companhia de Jesus.

Com base nessa contextualização da ordem inaciana em Portugal, o texto realiza discussão a respeito do trabalho que a mesma realizou, sobretudo, no que tange às questões institucionais educativas. Para tanto, realizamos apontamentos sobre o ensino jesuítico com base em um colégio em especial: o Colégio de Santo Antão, o qual nos remete a algumas das principais considerações para com as ações da Companhia.

Este trabalho, então, procura apontar algumas conjecturas a respeito de como o Colégio de Santo Antão foi considerado a mais respeitada e importante instituição educativa e religiosa de Lisboa. Ele é inaugurado no ano de 1553 e seu fechamento se dá com a expulsão dos jesuítas, em 1759. No entanto, neste texto nos atemos às referências e a suas principais atividades no século XVI, considerando alguns trâmites que acompanharam sua popularização.

Outra questão que ilustra nosso texto são as aulas astronômicas, que ficaram conhecidas como a 'Aulas da Esfera'. Essas aulas, voltadas para as ciências, foram ministradas na instituição entre os anos de 1590 e 1759; representava a inovação e a aceitação das modernas ciências no reino lusitano. Portanto, fazer contato com o Colégio de Santo Antão ajuda-nos, também, a compreender como eram consideradas tais inovações no ensino, ainda que no caso jesuítico, no contexto de Portugal do século em questão. 
Com tais considerações, é possível observar, ainda que brevemente, a atuação da Companhia e a forma como se realizou o exercício educacional acerca do trabalho, sobretudo de catequização, realizado pelos padres.

De acordo com o exposto, a fim de dar conta das questões relacionadas, organizamos o texto da seguinte maneira: num primeiro momento apresentamos a estrutura dos Colégios da Companhia, bem como algumas considerações a respeito do método pedagógico; na sequência, discorremos a respeito do Colégio de Santo Antão; isso feito apresentamos, ao final, considerações a respeito da principal inovação da instituição mencionada, a Aula de Esfera.

O esforço empreendido neste texto tem como objetivo fornecer respaldo para as apreciações nas ações da ordem inaciana, o Colégio e esta importante aula. Para compreender a ciência no século XVI, é necessário conhecer esta instituição e o desenvolvimento da 'Aulas da Esfera', questões que permeiam os séculos XVI, XVII e XVIII, e quiçá, ainda refletem hoje, em nossa educação.

\section{COLÉGIOS DA COMPANHIA DE JESUS E A SISTEMATIZAÇ̃̃O DE UM MÉTODO PEDAGÓGICO}

É fato recorrente e habitual na História e Historiografia considerarmos que a Educação na Modernidade passou pela ação da Companhia de Jesus, principalmente nos domínios portugueses (BOXER, 2002). Essa ordem, como citamos, nasce num período cheio de importantes fatos históricos, como: Reforma Protestante (religioso), o fortalecimento das Monarquias Nacionais (político), a descoberta e a colonização da América (social e econômico), entre tantos outros. Os jesuítas tinham por objetivo evangelizar e levar à fé ao mundo, no entanto, outras questões permearam estes objetivos.

Costa e Men (2012, p. 150), ressaltam que a ação educacional não era, a priori, o objetivo da Companhia, mas passou a norteá-la; para tanto:
A educação jesuítica possui características bem próprias do contexto do século XVI. Os primeiros cuidados com a educação foram abordados na IV parte das Constituições Jesuítica, porém, a pedagogia inaciana acabou ganhando um método próprio e foi regulada por um plano de estudos que ficou conhecido como Ratio Studiorum, publicado em 1599. Nesse plano, mesmo com data de publicação posterior à fundação dos primeiros colégios, os métodos ali propostos já vinham sendo aplicados e postos em práticas nas escolas jesuíticas. Isso tornou a Companhia de Jesus singular em sua metodologia de ensino.

Tanto a educação como a instrução foram muito bem administradas pelos jesuítas à medida que Inácio de Loyola, de Roma, direcionava seus discípulos, os quais tinham como princípio superior a obediência. Passam no século XVI a fundar suas primeiras instituições. Os colégios da Companhia iam além de casas de estudos, mas serviam, também, de moradia a seus mestres e pares, centralizavam ali a organização e a administração da ordem. Segundo os posicionamentos dos cargos:

\begin{abstract}
0 reitor do colégio era o terceiro na hierarquia jesuítica, estando abaixo do superior provincial e do superior geral. Quem tinha a função de gerenciar a parte escolar era, segundo escrevia o Ratio, o Prefeito de Estudos. O colégio era, portanto, para a Companhia de Jesus, o que eram o mosteiro ou a abadia para outras ordens religiosas mais antigas, daí a necessidade de sempre fundá-los onde quer que estivessem. (COSTA; MEN, 2012, p. 150).
\end{abstract}

Em Portugal, os jesuítas foram muito bem recebidos pelo monarca D. João III, o que facilitou tanto suas acomodações, como a progressão gigantesca de sua ordem. E, após um tempo com estadia no território luso, os padres tiveram a possibilidade de ter a primeira casa de formação, o mosteiro de Santo Antão, o qual acomodava apenas aqueles que serviriam à Companhia e ocupariam uma cadeira na Ordem, sendo encaminhados posteriormente à Universidade.

O superior dos jesuítas, em territórios portugueses, Simão Rodrigues, vinha conquistando, e muito bem recebendo, os novos membros da instituição. As 
casas dos jesuítas eram os colégios onde os jovens poderiam residir para a sua formação. Conforme a quarta parte das Constituições:

[...] a Companhia funda colégios e também algumas universidades, onde os que deram boa conta de si nas casas e foram recebidos sem os conhecimentos doutrinários necessários possam instruir-se neles e nos outros meios de ajudar as almas. (CONSTITUIÇÕES, 1997, p. 117).

Ainda, no que diz repeito às Constituições, o objetivo dos colégios não era manter apenas os bons costumes daqueles escolásticos que o formavam, mas, também, afetar diretamente o público externo. Onde se pudesse, e fosse necessário, era autorizada a realização de aulas públicas, ainda que consistisse, ao menos, para estudos humanísticos. 0 Geral é quem indicaria e aceitaria os locais aos quais tais seriam realizadas. E, ainda, no que consiste às aulas:

\begin{abstract}
Tomar-se-ão também em conta as possibilidades da Companhia. Nossa intenção seria que se ensinassem originariamente nos colégios humanidades, línguas e doutrina cristã, e, se fosse necessário, se desse um curso de casos de consciência. Se facilmente se encontrar alguém para pregar e confessar, que o faça, mas não se introduzam cursos de estudos superiores. Para esses enviar-se-ão dos colégios às universidades da Companhia os que neles tiverem feito os seus estudos literários. (CONSTITUIÇÕES, 1997, p. 137).
\end{abstract}

No que diz respeito à estadia dos estudantes nas instituições, é necessário ficar expresso que existiam muitas regras, que, quando não cumpridas geravam castigos. No entanto, nenhum membro da companhia deveria ou poderia aplicar castigos físicos, as penas nunca seriam realizadas pelas mãos dos inacianos. Se possível que fosse por mãos de um corretor, caso não, o apropriado seria aplicá-la por meio de um estudante ou de outra maneira similar.

Ao tratar das orientações pedagógicas, destacamos que foram adotadas nas primeiras instituições jesuítas o denominado modus parisienses (originário da Universidade de Paris e seus Colégios), considera- do, por Loyola e seus companheiros, o melhor para o aprendizado da gramática da língua latina. 0 outro método que existia até então, o modus italicus (utilizado na região italiana), conhecido por não estruturar e nem vincular os discípulos a determinada disciplina, foi recusado pelos inacianos. 0 modus parisienses exigia a distribuição dos alunos em classes e consistia no incentivo ao trabalho escolar.

\begin{abstract}
Baseando-se na escolástica, o modus parisiensis tinha como pilares a lectio, isto é, a preleção dos assuntos que deviam ser estudados, o que podia ser feito literalmente por meio de leitura; a disputatio, nas quais os alunos, geralmente em pequenos grupos, repetiam as lições explanadas pelo professor diante dele ou de um aluno mais adiantado. Os mecanismos de incentivo ao estudo implicavam castigos corporais e prêmios, louvores e condecorações, além da prática da denúncia ou delação. (SAVIANI, 2008. p. 52).
\end{abstract}

Os jesuítas adotaram tal método desde o primeiro colégio fundado em Messina e, posteriormente, o consagraram no Ratio Studiorum. O documento educacional oficial da Companhia de Jesus remonta questões educacionais já articuladas por Inácio na IV parte das Constituições, e direciona a organização didática e o espírito que deveria nortear a atividade pedagógica (SAVIANI, 2008).

Sousa (2003), ao também referenciar sobre a IV parte das Constituições, descreve que a formação de escolásticos e a educação dos estudantes seculares visavam homens cultivados, de visão católica, participantes na vida civil, cultural e religiosa da sociedade. Para isso, era preciso elaborar em detalhes as instruções relativas às disciplinas e ao método de estudos nos colégios e faculdades.

O primeiro Colégio da Companhia destinado a estudantes laicos foi o Colégio de Messina, em 1548. Entretanto, alguns autores afirmam que o mais ilustre foi o Colégio Romano de 1550.

[...] o mais ilustre de todos os centros de saber fundados por Inácio foi o Colégio Romano (1550); podemos 
mesmo considerá-lo como um modelo de todas as instituições pedagógicas jesuíticas. A 22 de Fevereiro, os Romanos lêem à porta dum simples edifício junto ao Capitólio: Scuola di grammatica, d'humanità e di dottrina cristiana, gratis (Escola de gramática, humanidades e doutrina cristã, gratuita). Este é o início do que Leonel Franca menciona como "uma espécie de Escola Normal Superior" que preparava, de entre os estudantes da Ordem, os futuros professores, fornecendo-lhes os melhores métodos e pondo-os em contacto com os melhores educadores. (SOUSA, 2003, p. 2).

A abertura do ensino aos estudantes não religiosos contribuiu decisivamente para o crescimento dos Colégios da Companhia de Jesus, principalmente em Portugal. Dessa forma, após os primeiros Colégios de Messina (1548) e Palermo (1549) foi fundado, em 1550, como vimos, o Colégio Romano, que se tornou referência para toda a ordem. Em 1551, Inácio de Loyola escreve a Simão Rodrigues, pedindo-lhe para criar o ensino público em várias cidades de Portugal, a começar por Lisboa, Coimbra e Évora.

No início do ano de 1553, portanto, foram abertas as primeiras escolas com acesso ao público e não tão somente aos que queriam se tornar membros da Companhia de Jesus em Portugal. Lisboa foi escolhida para inaugurar esta empresa. De início, devido às circunstâncias, as normas prescritas por Inácio não puderam ser todas atendidas. Não conseguiram edificar o Colégio em locais separados, assim, foi instalado na mesma casa de Santo Antão, em Lisboa.

O Colégio de Santo Antão torna-se, em pouco tempo, o mais respeitado e importante de Lisboa. Ao chegar a território luso, os jesuítas concentram-se, a princípio, em Coimbra, juntamente com a Universidade, mas, posteriormente estenderam seus domínios também a Lisboa, fundando esse Colégio.

Aos poucos a quantidade de centros de ensino se ampliava, pari passu com a realidade que exigia novas demandas. A Companhia de Jesus estabeleceu dois tipos diferentes de colégios: um privado, exclusivamente para a formação de futuros jesuítas, e outro públi- co, para a formação dos jovens em geral. Entretanto, tal divisão não era tão rigorosa que não permitisse a existência de colégios onde estudassem tanto os seminaristas quanto os externos.

A fundação do colégio era realizada quando alguma cidade, algum nobre ou membro da realeza, ou, ainda, alguma pessoa em particular contribuía com as rendas para a sua manutenção.

\begin{abstract}
Ao colégio dava-se princípio da seguinte maneira. Nomeavam-se três ou quatro mestres de letras humanas. 0 primeiro começava a ensinar aos mais pequenos os rudimentos da gramática; o segundo tomava à sua conta os que tinham alguma mediania de latim, e o terceiro cuidava dos que haviam de aperfeiçoar-se nos preceitos da arte gramatical. 0 quarto seria o professor de humanidades, que exercitaria os jovens mais adeantados na língua latina e grega e também na hebraica. Publicando-se a abertura das escolas, admitiam-se nelas gratuitamente quantos o desejassem e soubessem já ler e escrever. (RODRIGUES, 1931, p. 287).
\end{abstract}

Os admitidos, portanto, deveriam ser obedientes aos mestres em relação aos estudos, se confessar ao menos uma vez a cada mês, participar da missa aos domingos, guardar modéstia e ter compostura nas palavras e ações. Para quem se desviasse, seriam aplicados castigos, entretanto, em princípio, sem contato físico.

Segundo Rodrigues (1931), os menos favorecidos tinham a oportunidade de encontrar nesses colégios de forma gratuita o que teriam que pagar em outro; e dos estudos, continua Rodrigues, colheriam bons frutos dos quais poderiam retribuir ao serviço de Deus. Muitos eram contrários a essa postura dos jesuítas, pois defendiam que não fossem admitidos quaisquer filhos do povo, mas, sim, que fossem destinados à formação somente os filhos da nobreza. Entretanto, os religiosos da Companhia não concordaram com tal argumentação e abriram as portas dos colégios para todos, sem estabelecer tantas diferenças.

Nos colégios da Companhia de Jesus objetivava-se que os estudantes saíssem de lá como pregadores, 
governadores do povo, administradores de justiça e homens aptos para outros cargos, alargando-se cada vez mais o rendimento de toda a educação e ensino (RODRIGUES, 1931).

Em linhas gerais, estas são algumas características dos Colégios e método pedagógico dos jesuítas. $\mathrm{Na}$ sequência, quando algumas considerações serão realizadas acerca do colégio de Santo Antão, será possível analisar a materialização de alguns dos elementos citados.

\section{COLÉGIO DE SANTO ANTÃO}

O número de estudantes do Colégio de Santo Antão, após sua fundação, crescia rapidamente, tendo que foi necessário redobrar o número de escolásticos e aulas. Com esse crescimento, foi demandado um novo edifício para acomodar os numerosos estudantes que frequentavam o espaço, o que, mais tarde, geraria a necessidade da construção de nova escola, por meio de ajuda da cidade.

Entender o Colégio de Santo Antão é, antes de qualquer coisa, dar importância à evolução do conhecimento científico na sociedade portuguesa. 0 papel dos jesuítas, nesse cenário, vai além da propagação da fé católica ou da instrução acadêmica, vai para o desenvolvimento da ciência em terras lusitanas.

O Colégio foi a primeira casa que a ordem inaciana possuiu em todo o mundo. As instalações eram muito simples, freiras dominicanas já haviam ocupado aquele local, e maldiziam a localidade. Apesar de tamanha simplicidade, os jesuítas abraçaram o que lhes foi dado e empreenderam o esforço que lhes cabia para tal desenvolvimento (LEITÃO; FRANCO, 2012). Evidenciamos que, embora o Colégio tenha sido inaugurado no ano de 1553, os jesuítas já residiam na casa há uma década.

Então, com a ocupação do local pelos membros da Societa lesus em 1542, se ganha uma estrutura edu- cacional jesuítica e inicia-se com aulas inaugurais em fevereiro de 1553. A procura pelas matrículas foi muito grande, tanto que, como já informado, foi necessária outra construção. No ano de 1593 começam no novo ambiente as aulas do que passo a se chamar Colégio de Santo Antão-o-Novo.

Diferenciando-se do Colégio de Jesus em Coimbra, ao qual atendia apenas estudantes que tivessem interesse em compor a Ordem, o Colégio de Santo Antão foi planejado para ser uma escola pública, principalmente para atender alunos que não tivessem o interesse em serem jesuítas, mas que tinham interesse em uma educação séria, rigorosa e, acima de tudo, cristã.

O que porém mais despertava as admirações dos cidadãos de Lisboa era a transformação rápida e profunda que se operava no porte e costumes dos estudantes. Já no ano escolar que sucedera ao da abertura do colégio, se celebrava a mudança daquela buliçosa juventude. Aparecia mais composta nas suas maneiras, mais bem morigerada e mais piedosa. (RODRIGUES, 1931. p. 300).

Um dos problemas encontrados pela Companhia foi o desejo elitista de formação reduzida para alguns membros da elite aristocrática. Francisco Correia, por exemplo, um vereador de Lisboa, do século XVI, solicitava que não se formasse a camada mais pobre da sociedade, mas sim indivíduos capazes de exercer cargos sociais e acrescentar à sociedade. Os membros da Ordem não concordaram, pois:

\footnotetext{
[...] preferiam abrir largamente as portas do seu colégio a todos, sem estabelecer diferenças de categoria social, e difundir para todas as classes as luzes da instrução e as lições da educação cristã. Com esta amplidão de caridade abriram na entrada de fevereiro o colégio no antigo mosteiro de S. Antão, e escasseava o espaço para acolher tão grande multidão de alunos, que acorreram ao convite dos novos mestres. Era o reitor naquele princípio o P. Melchior Carneiro. (RODRIGUES, 1931, p. 293).
}

Ao nos referimos ao ensino empreendido nos Colégios da ordem inaciana, as grades de disciplinas 
da instituição incluíam entre suas matérias: Latim, Gramática, Humanidades, Retórica, por determinado tempo até mesmo Grego, Teologia Moral, Teologia Dogmática e Filosofia, disciplinas consideradas únicas ao ensino no contexto Português.

[...] sobretudo classes de latim e de estudo de autores latinos, de língua grega e de retórica, além de aulas de temas morais e religiosos. Também se começaram a ministrar, a partir de 1555, aulas de esfera, isto é, de introdução à cosmografia e astronomia, pelo padre Francisco Rodrigues, aulas estas que de certa maneira viriam a ser o embrião da futura "Aula da esfera”. (LEITÃO, 2007, p. 30).

Uma das principais características do Colégio ao longo do século XVI, como consta na citação de Leitão acima, foram as aulas de cosmografia e astronomia, que vinham sendo ministradas. É possível afirmar que as primeiras atividades matemáticas "[...] incluíam nos seus conteúdos aspectos astronômicos e tiveram início no Colégio de Santo Antão a partir de 1555, ministradas pelo Pe. Francisco Rodrigues (1515-1573)" (ASSUNÇÃO, 2014, p. 38). O ensino de matemática já era ministrado no Colégio Romano em 1551; no entanto, informações sólidas acerca dessas aulas de astronomia e matemática em Santo Antão, são possíveis apenas por volta 1590 .

O Colégio passa a reunir muitos alunos, e o espaço já não seria suficiente para acomodar todos aqueles estudantes, então passa a ser necessário a mudança do Colégio para outra sede (RODRIGUES, 1931). Sendo assim, em dezembro de 1573, os inacianos conseguem, por meio do cardeal Infante D. Henrique, uma doação de generosa renda mensal, da parte do rei e sobrinho D. Sebastião; contanto que, se atendesse a alguns pedidos, sendo um deles, oficial e curricularmente, ministrar aulas de matemática.

Leitão (2007, p. 33) afirma não ser difícil compreender porque foram solicitadas estas aulas por meio do cardeal Infante e de seu sobrinho, D. Sebastião:
Em Coimbra, na Universidade, o ensino de matemática estava num estado lastimoso. Com a jubilação de Pedro Nunes ${ }^{2}$, em 1564, as aulas de matemática foram sucessivamente entregues a figuras menores e pouco a pouco caíram em total desleixo.

Em maio de 1579 é iniciada a obra do novo Colégio, mas a transferência efetiva de todo o corpo escolástico e demais instalações à nova instituição foi realizada somente em novembro de 1593. Embora a edificação ainda não estivesse finalizada, as aulas iniciaram-se na nova construção.

Para compreensão do Colégio objeto deste texto, bem como das atividades que desenvolvia e sua relação com o contexto, é aqui destacada uma das aulas mais importantes da instituição: a 'Aulas da Esfera'; com ela a instituição de ensino gratuito cresceu muito, tornando-se o melhor centro de Ciências e Astronomia de Portugal.

Leitão e Franco (2012) afirmam que no colégio eram trabalhados conteúdos inovadores incorporados às novas doutrinas consideradas por pela ordem inaciana. Destacam-se as introduções da 'Aulas da Esfera', intrínsecas à matemática, representando a grande inovação praticada no Colégio ao abordar a teoria e a prática de itens como o telescópio, os logaritmos, equações, geometria e afins.

Com a expulsão dos jesuítas, muitos arquivos se perderam (infelizmente do ponto de vista histórico e cultural) e ainda hoje pesquisadores reúnem-se para tentar obter mais informações com o objetivo de compreender melhor o contexto e a ciência portuguesa moderna.

Há relatos documentais que dão conta de que em 1553 eram cerca de 300 alunos regularmente matriculados, enquanto, em 1591, contava o Colégio de

2. Para saber mais leia-se: Pedro Nunes, 1502-1578: Novas terras, novos mares e o que mays he: novo ceo e novas estrellas. Catálogo bibliográfico sobre Pedro Nunes. Comissário científico: Henrique de Sousa Leitão; coordenação técnica: Lígia de Azevedo Martins. Lisboa: Biblioteca Nacional, 2002. 
Santo Antão com um número de 2500 alunos. Mas, ao longo da história, o número identificado é a média de 2000 estudantes. Por mais de um século, sem dúvida, aquele colégio foi a principal instituição de ensino da capital, que se vangloriava por formar, desde 1555, tanto padres para a Companhia, como capitães, desembargadores ou, mesmo, servos destinados a outras ordens religiosas.

O Colégio de Santo Antão, nesse sentido, possibilita compreender certas inovações no ensino. A instituição, principalmente pelas mencionadas inovações, foi essencial na modernização da ciência portuguesa. Considerações semelhantes podem ser realizadas com base nas Aulas da Esfera, realizadas nesse mesmo Colégio; esforço empreendido na sequência.

\section{4 'AULAS DA ESFERA': AS CIÊNCIAS MATEMÁTICAS NO COLÉGIO DE SANTO ANTÃO}

Nos Colégios da Companhia, a partir da versão definitiva do Ratio Studiorum, em 1599, temos nos currículos instrução para que os alunos que estudassem física devessem, também, aprender matemática; os conteúdos eram especificados como: Elementos de Euclides, Geografia e ‘Esfera’.

Como mencionado, as 'Aulas da Esfera' de Santo Antão, nasceram como pedido direto do cardeal, que se denominou fundador da reconstrução dessa instituição, mas tudo isso assegurado por meio de D. Sebastião, que fora o que investiu na renda da instituição. Até o final do século XVI, há apenas indícios de aulas de matemática ou astronomia na presente instituição. 0 pensamento em criá-la não é meramente ao bem do Colégio, mas também no empreendimento da Coroa ao investir na Companhia, o que a colocava a serviço do rei, quando assim fosse solicitado.

Para Leitão (2010), os jesuítas, ao compreender a necessidade dessas aulas, preparam João Delgado, no tempo estimado entre 1576 e 1585, na Academia de Clávio, em Roma para ensinar a matemática em Portugal, para pequenos grupos de jesuítas, onde, em 1590, oportunizam as aulas de assuntos matemáticos no Colégio de Santo Antão, nascendo, daí, a 'Aula da Esfera'. Essas aulas se tornam ainda mais importantes quando notamos que eram socializadas com alunos não-jesuítas.

\begin{abstract}
Além dos alunos jesuítas, estas aulas de assuntos matemáticos no Colégio de Santo Antão foram frequentadas por alunos leigos, entre os quais se contariam certamente jovens interessados em aprender ou aprofundar os seus conhecimentos. Uma confirmação da importância e do peso destes alunos não-jesuítas na composição das classes de matemático do Colégio de Santo Antão pode obter-se constatando que as notas dessas aulas estão redigidas em português, em contraste com a prática habitual do ensino dos jesuítas que era feito em latim. (LEITÃO, 2007. p. 48).
\end{abstract}

É importante ressaltar que foi o primeiro centro de ensino no qual o estatuto das matemáticas encontrava-se num molde moderno; além de ter sido o meio pelo qual Galileu, bem como o telescópio e o debate cosmológico, foram divulgados em Portugal.

[...] os estudos das últimas décadas deixaram claro que essa 'Aula da Esfera', que funcionou ininterruptamente de finais do século XVI até 1759 , foi uma instituição a todos os títulos única na história científica portuguesa. [...] aí se ensinaram e se praticaram, muitas vezes com carácter verdadeiramente pioneiro entre nós, temas científicos tão variados como a matemática, a astronomia de observação e a astronomia teórica, a náutica, a cosmografia, a teoria do calendário, da hidráulica, a óptica, a fortificação, a estática etc. A 'Aula da Esfera' foi a mais relevante escola de assuntos náuticos e a porta de entrada em Portugal de muitas novidades científicas desde o uso de logaritmos ao emprego da projecção de Mercator passando pela construção de instrumentos científicos, pelos primeiros textos conhecidos de estática teórica etc. (LEITÃO, 2010, p. 18).

As aulas se tornaram tão especiais e a instituição tão importante devido, também, a vinda de professores de outros países para ministrarem aulas na instituição. Ainda que criticada por alguns dos professores 
estrangeiros pela sua qualidade deficiente, as aulas eram comparadas com as de grandes centros Europeus, e não só mais portugueses.

Rossi (2001) afirma que no Colégio, por meio da 'Aula da Esfera' e seus estudiosos, analisava-se a teoria heliocêntrica proposta por Nicolau Copérnico (1473-1543) e, no mesmo sentido, reconhecia-se o trabalho realizado por Galileu Galilei (1564-1642).

A aula aconteceu entre os anos de 1590 e 1759, representando a inovação e aceitação, no reino lusitano, de temáticas correspondentes aos saberes científicos. Nenhuma outra instituição de ensino, até onde se sabe, influenciou de forma tão intencional os centros de ensino da Companhia de Jesus, suas atividades beneficiavam os recursos e os contatos religiosos e sociais.

\section{CONSIDERAÇÕES FINAIS}

A Companhia de Jesus no século XVI foi fundada com o objetivo religioso de propagar uma renovada fé cristã. Entretanto, para tal desafio, era preciso uma formação adequada, tanto que todos os membros da Companhia de Jesus tinham uma rigorosa preparação intelectual. Tal iniciativa fez com que se abrissem residências em vários lugares do mundo, onde se formavam membros para integrar aquela ordem religiosa. Posteriormente, partes dessas residências foram transformadas em Colégios, devido à abertura para estudantes não religiosos.

Dessa forma, é possível afirmar que, além das missões, a educação foi outra atividade característica da Companhia de Jesus. Em Portugal, as principais atividades atribuídas aos padres jesuítas eram a educação da juventude, missões além-mar e confissões dos soberanos. Como confessores do rei, acabavam por influenciar nas decisões políticas dos mesmos, tanto que a consolidação da Companhia de Jesus em Portugal esteve diretamente ligada a sua relação com D. João III.
O Colégio de Santo Antão, com sua estrutura curricular, especialmente com as 'Aulas da Esfera', contribuiu pra o desenvolvimento e modernização da Ciência em Portugal, colocando a Companhia de Jesus como uma ordem religiosa que se preocupava com a Ciência da natureza e não apenas com a Teologia e Filosofia Escolástica.

Demonstrar que o Colégio de Santo Antão, localizado em Lisboa, no decorrer de sua história, especialmente no século XVI, se tornou um destacado estabelecimento de pesquisa e ensino das Ciências, contribui com a compreensão do desenvolvimento e modernização científica, tanto de Portugal, como da própria Companhia de Jesus.

\section{REFERÊNCIAS}

ASSUNÇÃO, Paulo de. Os Colégios Jesuíticos e a Produção e Circulação do saber no Império Colonial Português. In: RIBAS, Maria Aparecida de Araújo Barreto; SKALINSKI JUNIOR, Oriomar; TOLEDO, Cézar de Alencar Arnaut. (Orgs.). Origens da Educação Escolar no Brasil Colonial - Volume II. Maringá: EDUEM, 2014.

BOXER, C. R. 0 Império Marítimo Português (14151825). São Paulo: Companhia das Letras, 2002.

CONSTITUIÇÕES da Companhia de Jesus e NORMAS Complementares. São Paulo: Loyola, 1997.

COSTA, Célio Juvenal. MEN, Priscila Kelly Cantos. Características da Educação nos Colégios Jesuíticos em Portugal e no Brasil no Século XVI. In: RIBAS, Maria Aparecida de Araújo Barreto; SKALINSKI JUNIOR, Oriomar; TOLEDO, Cézar de Alencar Arnaut. (Orgs.). Origens da Educação Escolar no Brasil Colonial - Volume I. Maringá: EDUEM, 2012.

LEITÃO, Henrique. Longemira: os primeiros telescópios em Portugal. Lisboa: Gazeta Física, v.33, 2010. p.17-21. 
LEITÃO, Henrique. A Ciência na "Aula da Esfera" no

Colégio de Santo Antão: 1590-1759. Lisboa: Comissariado Geral das Comemorações do V Centenário de S. Francisco Xavier, 2007.

LEITÃO, Henrique; FRANCO, José Eduardo. Jesuítas, Ciência e Cultura no Portugal Moderno: Obra Selecta de Pe. João Pereira Gomes, SJ. Lisboa: Esfera do Caos, 2012.

RODRIGUES, Francisco. História da Companhia de Jesus na Assistência de Portugal. Porto: Apostolado da Imprensa, 1931-1950. Volume II, Tomo I.
ROSSI, Paolo. 0 nascimento da ciência moderna na europa. Bauru: EDUSC, 2001.

SAVIANI, Dermeval. História das ideias pedagógicas no Brasil. 2.ed. Campinas, SP: Autores Associados, 2008.

SOUSA, Jesus Maria. Os jesuítas e a Ratio Studiorum: as raízes da formação de professores na Madeira. Islenha, 2003. Disponível em: <http://www3.uma. pt/jesussousa/Publicacoes/310sJesuitaseaRatioStu diorum.PDF>. Acesso em 12 mar. 2014.
Recebido em: 1 de Junho de 2014 Avaliado em: 1 de Junho de 2014 Aceito em: 7 de Junho de 2014

\begin{abstract}
1. Docente da Universidade Estadual de Maringá, dos cursos e Pedagogia nas modalidades presencial e a distância e do mestrado e doutorado em Educação. É coordenador adjunto do curso de graduação em Pedagogia a Distância. A área de pesquisa em que atua é Educação, Cultura e História do Brasil Colonial, orienta na graduação, mestrado e doutorado. Participa do grupo de pesquisa interinstitucional Educação, Cultura e História: Brasil, séculos XVI, XVII e XVIII (DEHSCUBRA) e do Laboratório de Estudos do Império Português (LEIP) da Universidade Estadual de Maringá. E-mail: celio_costa@terra.com.br 2. Graduação em História (2005) e em Pedagogia (2010) pela Universidade Estadual de Maringá, mestrado em Educação pela Universidade Estadual de Maringá (2013). É aluno de doutorado do Programa de Pós-Graduação em Educação da Universidade Estadual de Maringá. Atualmente é professor colaborador do Departamento de Teoria e Prática da Educação da Universidade Estadual de Maringá. Possui experiência na Educação Básica. E-mail: gil_montagnoli@hotmail.com

3. Mestranda em Educação na área de História e Historiografia da Educação pela Universidade Estadual de Maringá (UEM) e Integrante do grupo de pesquisa interinstitucional Educação, Cultura e História: Brasil, séculos XVI, XVII e XVIII (DEHSCUBRA), do Laboratório de Estudos do Império Português (LEIP) e do Grupo de Pesquisas em Educação (GEPEDUC/UENP - CCP). Possui Especialização em Políticas Públicas pela Universidade Estadual do Norte do Paraná - Campus Cornélio Procópio (UENP - CCP). Bolsista CNPQ. E-mail: nat_oliveir@hotmail.com
\end{abstract}


